\title{
Modulator Device
}

National Cancer Institute

\section{Source}

National Cancer Institute. Modulator Device. NCI Thesaurus. Code C50073.

An electronic device designed to vary the frequency, amplitude, or phase of an electromagnetic signal. 